\title{
The analysis of the electrical properties of BLT ceramics fabricated from sol-gel derived powders ${ }^{\star}$
}

\author{
Beata Wodecka-Dus, Malgorzata Adamczyk ${ }^{\mathrm{a}}$, Jolanta Dzik, and Katarzyna Osinska \\ University of Silesia, Department of Materials Science, 2, Sniezna St., 41-200 Sosnowiec, Poland
}

Received 30 June 2015 / Received in final form 2 October 2015

Published online 22 February 2016

(C) The Author(s) 2016. This article is published with open access at Springerlink.com

\begin{abstract}
The $\left(\mathrm{Ba}_{x} \mathrm{La}_{1-x}\right) \mathrm{Ti}_{1-x / 4} \mathrm{O}_{3}$ (BLT, $\left.0.001 \leqslant x \leqslant 0.005\right)$ amorphous gel was prepared by sol-gel process. The electrical properties of obtained materials has been investigated by impedance spectroscopy. Detailed analysis of impedance spectra allowed to propose an adequate equivalent circuit, which described the electric properties of discussed materials very well. Basing on the obtained circuits and the fitting procedure the grain and grain boundary resistivity was determined as a function of temperature and La concentration. With increase of La admixture the contribution of grain and grains impedance to the bulk impedance changes. It was found that the small amount of La additive decreases the blocking factor of the grain boundary in the temperature range 600-850 K, whereas the amount of La on the level of $0.4-$ $0.5 \mathrm{~mol} \%$ causes the sharp increase of the mentioned factor. The fact may be attributed to a decrease of grain activation energy and increase of the grain boundary one.
\end{abstract}

\section{Introduction}

Barium titanate $\left(\mathrm{BaTiO}_{3}\right)$ is one of the most-known ferroelectric materials. Over the years $\mathrm{BaTiO}_{3}$ has been exceedingly investigated due to its very interesting practical applications in capacitors, thermistors, varistors, etc. [1,2]. The perovskite structure of $\mathrm{BaTiO}_{3}$ is very hospitable for ions of different size and valency $[3,4]$. The doping process may be performed twofold, namely by modification of the A or B sites perovskite lattice - the way of incorporation is dependet on valence and radius of substituting ions. Even very low concentration of admixture changes not only the microstructure and crystalline structure, but also have a strong influence on dielectric and electric properties of discussed ceramic material as well as its temperature of phase transition. One of the most investigated dopants is lanthanum, which, as a donor dopant, commonly substitutes barium ions in crystal lattice of $\mathrm{BaTiO}_{3}$ - not titanium, because $\mathrm{La}^{3+}$ ions are too large to replace Ti ions on B site. Since $\mathrm{La}^{3+}$ has a different valence than $\mathrm{Ba}^{2+}$ this change produce a charge imbalance. However the electroneutrality of sample must be maintained. The process leading to charge neutrality occurring in $\mathrm{BaTiO}_{3}$ has been a matter of debate for a long time. The one of theories postulates the way to the balance via electronic "donor - doping mechanism" or polaronic mechanism involving the reduction of small amount of $\mathrm{Ti}^{4+}$ ions to $\mathrm{Ti}^{3+}[5]$ accordingly

\footnotetext{
* Contribution to the Topical Issue "Materials for Dielectric Applications", edited by Maciej Jaroszewski and Sabu Thomas.
}

a e-mail: malgorzata.adamczyk-habrajska@us.edu.pl to the reactions:

$$
\begin{aligned}
& \mathrm{La}_{2} \mathrm{O}_{3}+2 \mathrm{TiO}_{2} \rightarrow 2 \mathrm{La}_{\mathrm{Ba}}^{\bullet}+2 \mathrm{Ti}_{\mathrm{Ti}}^{x}+6 \mathrm{O}_{\mathrm{O}}^{x}+\frac{1}{2} \mathrm{O}_{2}(g)+2 e^{\prime} \\
& \mathrm{La}_{2} \mathrm{O}_{3}+2 \mathrm{TiO}_{2} \rightarrow 2 \mathrm{La}_{\mathrm{Ba}}^{\bullet}+2 \mathrm{Ti}_{\mathrm{Ti}}^{\prime}+6 \mathrm{O}_{\mathrm{O}}^{x}+\frac{1}{2} \mathrm{O}_{2}(g) .
\end{aligned}
$$

That type mainly occurs for small amounts of foreign ions of higher valence (for example $\mathrm{La}^{3+}$ on $\mathrm{Ba}^{2+}$ sites or $\mathrm{Nb}^{5+}$ and $\mathrm{Sb}^{5+}$ on $\mathrm{Ti}^{4+}$ sites).

The amount and distribution of defects (electrons, cation and oxygen vacancies) have an influence on electric properties of ceramics by changing the resistivity of grain and grain boundary as well as and the growth of impermeability of grain boundary. In the present paper the complex impedance analysis is performed to obtain information about the electric phenomena occurring in $\mathrm{BaTiO}_{3}$ ceramics. The technique allows to separate the individual contribution of grain and grain boundary to the total impedance spectrum and examine the influence of lanthanum dopant on electric properties of microstructure components and ionic transport phenomena connected with them.

\section{Experimental}

The ceramic materials $\left(\mathrm{Ba}_{1-x} \mathrm{La}_{x}\right) \mathrm{Ti}_{1-x / 4} \mathrm{O}_{3}$ for lanthanum content $x$ in the range of $0 \leqslant x \leqslant 0.005$, used in study described in the hereby paper, were prepared by sol-gel method. The starting materials were 


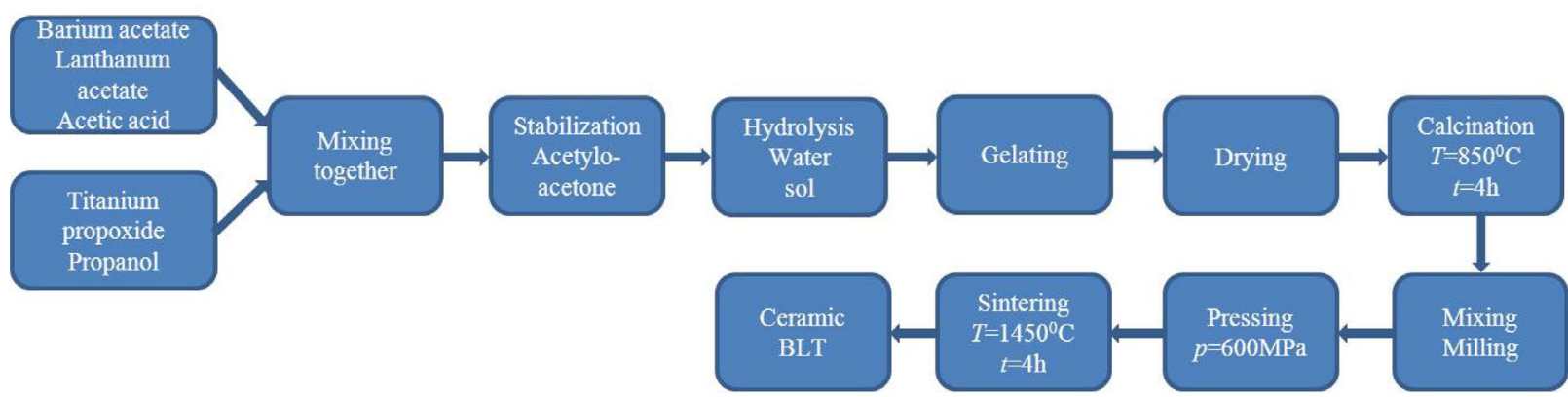

Fig. 1. Basic steps for fabrication of $\left(\mathrm{Ba}_{1-x} \mathrm{La}_{x}\right) \mathrm{Ti}_{1-x / 4} \mathrm{O}_{3}$ ceramic samples by free sintering technique.

barium acetate $\left(\mathrm{Ba}\left(\mathrm{CH}_{3} \mathrm{COO}\right)_{2}, 99 \%\right)$, lanthanum acetate $\left(\mathrm{La}\left(\mathrm{CH}_{3} \mathrm{COO}\right)_{3}, 99 \%\right)$, and titanium (IV) propoxide $\left(\mathrm{Ti}\left(\mathrm{OC}_{3} \mathrm{H}_{7}\right)_{4}, 98 \%\right)$. Glacial acetic acid $\left(\mathrm{CH}_{3} \mathrm{COOH}\right.$, 99.9\%) and n-propyl alcohol $\left(\mathrm{C}_{3} \mathrm{H}_{7} \mathrm{OH}, 99.9 \%\right)$ were used as solvents. After dissolving the barium acetate and lanthanum acetate in acetic acid at $T=100{ }^{\circ} \mathrm{C}$ for $t=$ $0.5 \mathrm{~h}$ and cooling down to room temperature and after mixing titanium (IV) propoxide with n-propyl alcohol, Ba-La solution was mixed with $\mathrm{Ti}$ solution using magnetic stirrer for $t=1 \mathrm{~h}$. Small amounts of acetylacetone $\left(\mathrm{CH}_{3} \mathrm{COCH}_{2} \mathrm{COCH}_{3}\right)$ were added as stabilizer. The sol was relatively stable and became a gel in few days. The amorphous BLT dry gel was calcinated at $T=$ $850{ }^{\circ} \mathrm{C}$ for $t=4 \mathrm{~h}$ and afterwards analyzed by thermogravimetric analysis (TGA) and by differential thermal analysis (DTA). After calcination the BLT powder was milled and pressed into discs of $d=10 \mathrm{~mm}$ in diameter and $h=2 \mathrm{~mm}$ thick using pressure $p=600 \mathrm{MPa}$. The moldings were next sintered by free sintering method at the temperature $T=1450{ }^{\circ} \mathrm{C}$ for $t=4 \mathrm{~h}[6]$.

A flow chart of technology processes of BLT ceramics is presented in Figure 1.

The Archimedes displacement method with distilled water was employed to evaluate sample density. Sample bulk densities ranged from 6.01 to $6.04 \mathrm{~g} / \mathrm{cm}^{3}$ representing $91-96 \%$ of theoretical density.

For the impedance spectroscopy (IS) measurements samples were polished and coated with silver electrodes on both sides. Impedance data as a function of frequency and temperature was obtained in the frequency range $20 \mathrm{~Hz}-$ $2 \mathrm{MHz}$ using a precision LCR meter Agilent E4980A. The coherence of obtained data was performed by using the Kramers-Kroning (K-K) validation test [7]. Data fitting was carried out employ complex non-linear least squares method (CNLS) [8] using the ZView equivalent circuit software produced by Scribner Associates ${ }^{1}$.

\section{Results and discussion}

It is commonly known that in BLT ceramics the lanthanum ions have undeniable impact on formation of electrical properties. The electric conductivity in macroscopic sens is in fact, the result of processes occurring in the interior of the ceramics, ergo the electric conductivity of

\footnotetext{
${ }^{1}$ Scribner Associates, Southern Pines, North Carolina, USA.
}

grain and grain boundaries. The question arises, what is the particular role of lanthanum in the formation of grain and grain boundary conductivity. The useful tool to explore the discussed properties is impedance spectroscopy, carried out in the wide range of frequency.

The most important problem of IS data analysis is to find the proper electrical equivalent circuit, which not only gives the good fitting results, but also is paired with the physical phenomena in the samples. The presentation the data in the impedance $\left(Z^{*}\right)$ formalism should greatly facilitate the solution of the problem. The shape of frequency dependence of the real and imaginary part of complex impedance changes with the increasing of lanthanum content (Fig. 2). In case of pure BT and the samples contain respectively $0.1 \mathrm{~mol} . \%$ of La (BLT1), $0.2 \mathrm{~mol} . \%$ of La (BLT2) and $0.3 \mathrm{~mol} \%$ of La (BLT3) the dependences of $Z_{i m}(f)$ have two local maxima, which location on the curves is temperature dependent. The shape of discussed dependence changes rapidly for ceramics modified by 0.4 mol.\% of La (BLT4) - only one maximum can be isolated on the $Z_{i m}(f)$ curves obtained in particular temperature from $505 \mathrm{~K}-825 \mathrm{~K}$.

What is more important, for sample with $0.5 \mathrm{~mol} \% \%$ of lanthanum (BLT5) the single maximum is strongly ripped at the range of frequency from 10 up to $1000 \mathrm{~Hz}$ and for the higher frequency the $Z_{i m}(f)$ are almost completely temperature independent. The similar problem is noticeable for $Z_{r e}(f)$ dependences. Namely for pure BT sample as well as the samples containing small amount of La ions the dependences in low frequency range are flat frequency independent and next, at the middle range of frequency, they start to decrease. The strong temperature dependence of $Z_{r e}(f)$ is observed on all measuring range of frequency - the value of $Z_{r e}$ decreases with increasing temperature, which is due to an increase of the conduction losses [9]. The temperature influence on $Z_{r e}(f)$ characteristics almost completely disappear for samples with $0.5 \mathrm{~mol} \%$ of lanthanum - the $Z_{r e}(f)$ characteristic for all temperatures merge at high frequency. This is due to the release of space charge as a result of reduction in barrier properties [10,11].

The assessment of conformity of received impedance data were made by using the software K-K Test (B.A. Boukamp) accordingly to the methodology widely described in paper $[7,8]$ for all obtained results. The obtained residual spectrum of the frequency dependence of the relative difference between the experimental data and data 

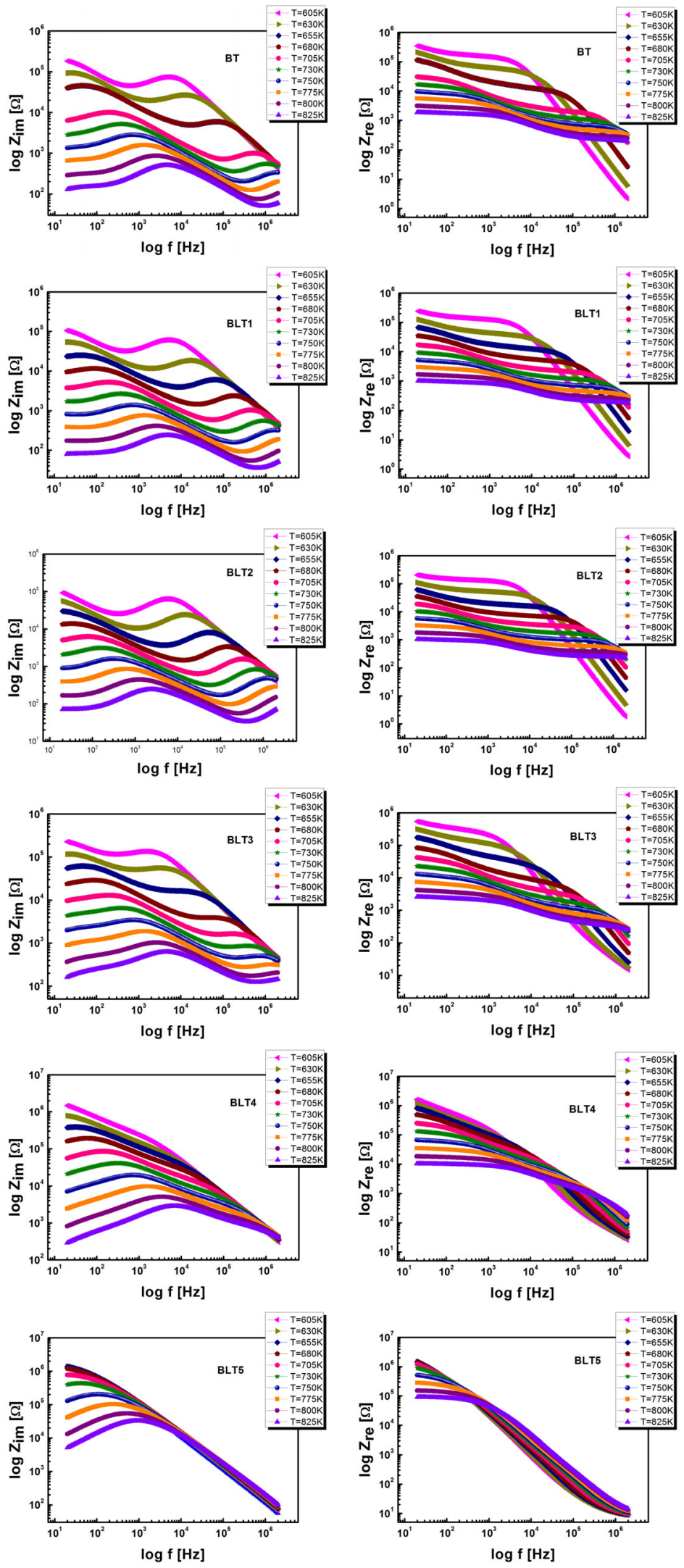

(a)

(b)

Fig. 2. The frequency dependence of imaginary (a) and real (b) part of the impedance at various temperature for $\mathrm{BaTiO}_{3}$ ceramics modified by lanthanum. 

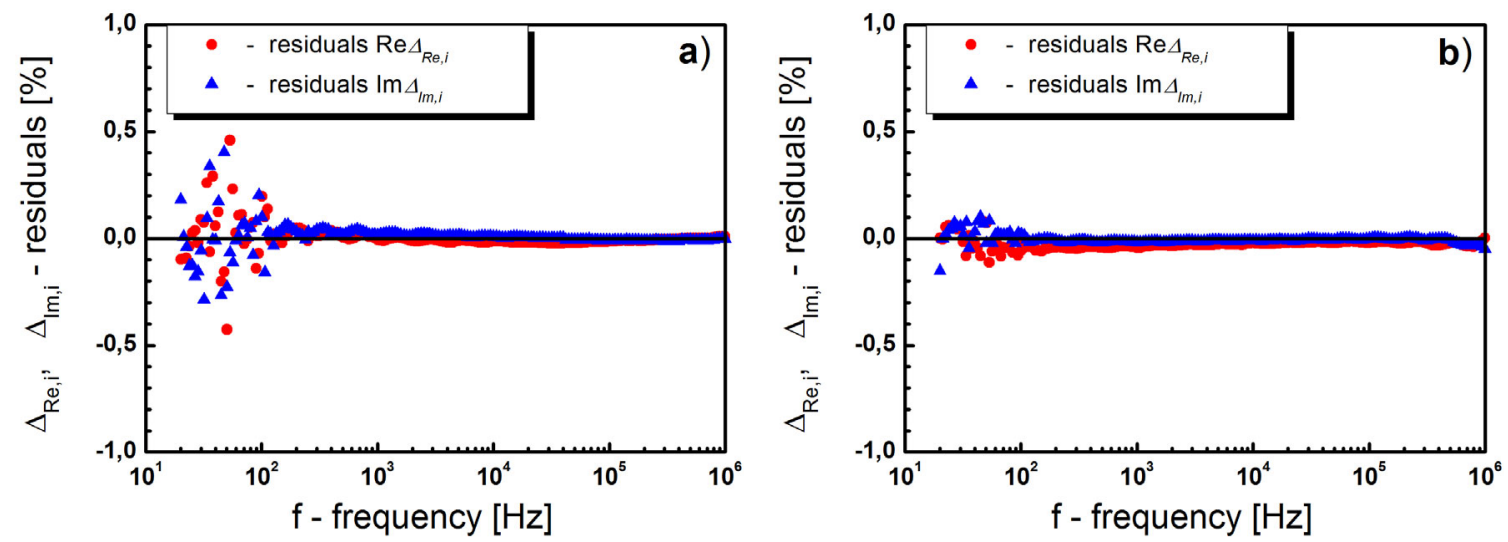

Fig. 3. Display of the Kramers-Kronig test residuals for the measured IS data as example in temperature 505 K for BLT2 (a) and BLT5 (b) ceramics.
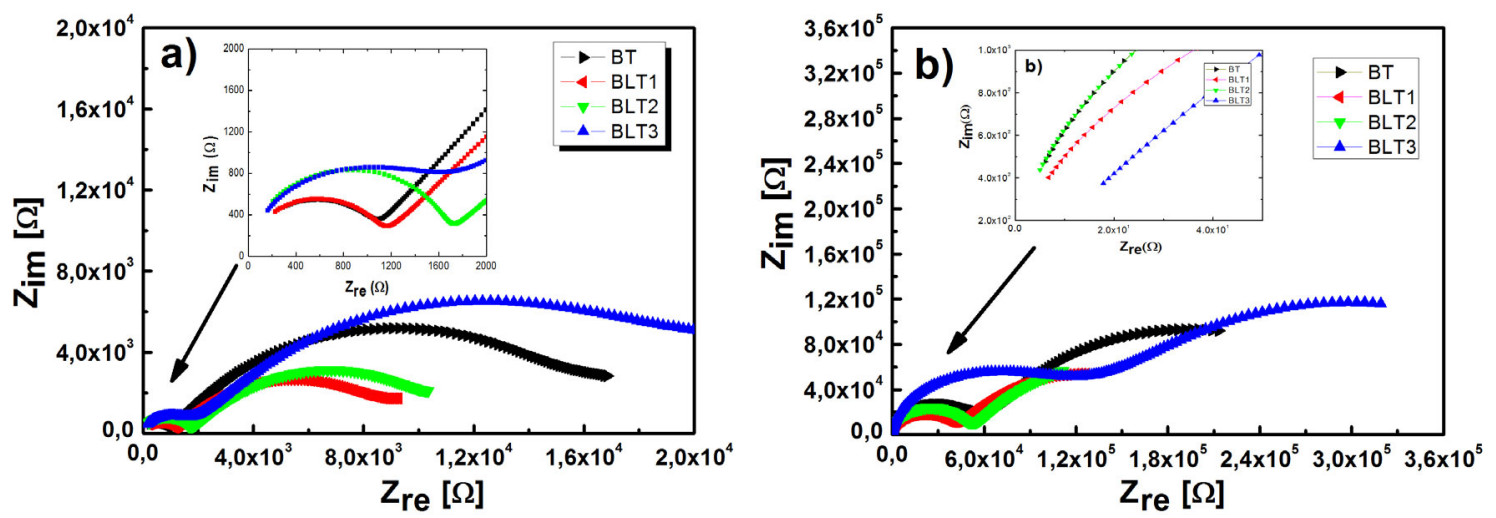

Fig. 4. Nyquist plot for BLT ceramics with different content of lanthanum obtained at temperatures equal respectively $727 \mathrm{~K}$ (a) and $628 \mathrm{~K}(\mathrm{~b})$.

obtained as a result of the K-K Test for ceramics BLT2 and BLT5 at temperature $505 \mathrm{~K}$, as an example, are given in Figure 3. The residual spectrums, obtained for all discussed ceramics, have noises-like character around the frequency axis, which indicates the accuracy of the experimental data. The value of noises does not exceed the $0.5 \%$.

The very positive results of K-K Test allowed further analysis of impedance data. The next step of analysis for impedance data was associating with plot of dependence between real and imaginary part of impedance. For ceramics with small amount of lanthanum (up to $0.3 \mathrm{~mol} . \%$ of La) plots consisted of two semicircles in two separate frequency ranges (Fig. 4). Such effect, discussed in references $[12,13]$, suggest that two different conduction mechanisms are present in the measured frequency and temperature ranges. The semicircle in the high frequency region is representing the bulk properties of grains and the other one, in the low frequency region, is an impedance arc related to the grain boundary. The center of both impedance semicircles lie below the real axis.

For ceramics modified by 0.4 and 0.5 mol. $\%$ of lanthanum the interpretation of $Z_{i m}\left(Z_{r e}\right)$ dependence is not so clear and simple. The obtained curves were neither deformed semicircle nor circular arcs, which center placet below the real axis. In the high frequency region the
Debye-like behaviour was observed - the angle between the tangent of the arc and the real axis was $90^{\circ}$. Whereas in the part of arc where $f \rightarrow 0$ the angle was less then $90^{\circ}$ and was temperature dependent (Fig. 5).

Such behaviour is prevalence for ceramics material characterized by perovskite structure [14] as well as ceramics belonging to the Aurivillius family [15-17]. The deviation form classic semicircle entails the ability to be properly resolved using two semicircles models, just like it was proposed for ceramics modified by small amount of lanthanum. The attitude to IS data described above is connected with choosing the adequate equivalent circuit, which will be describing the electric properties of discussed materials well. The authors of hereby paper, took into account a number of literature reports [9,18-20] and decided to use the equivalent circuit consisting of two branches in the series, represented the electric properties of grain and grain boundary (Fig. 6).

For the ideal Debye-like like ceramics the discussed branches consist of resistor and capacitor. In the real case the ceramic materials do not manifest the ideal "Debye" like behaviour, thus to illustrate more fully the deviation from an ideal capacitor, an additional element with the constant phase (CPE) is introduced into equivalent circuit [21]. Impedance of CPE elements can be 

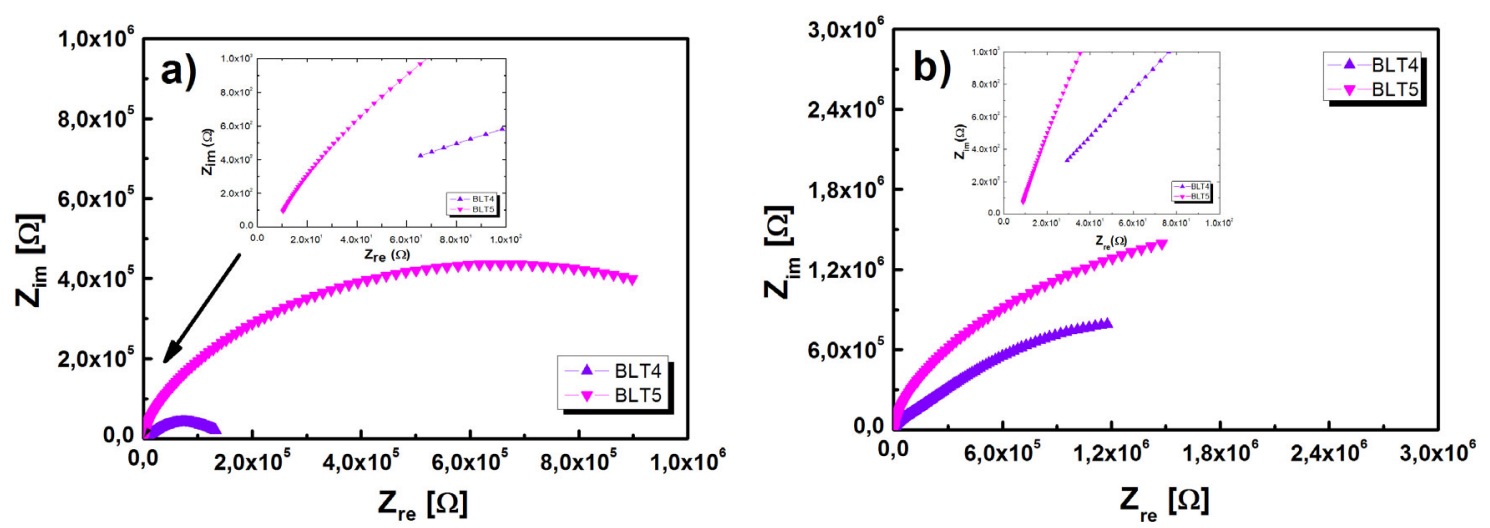

Fig. 5. Nyquist plot for BLT4 and BLT5 ceramics with different contents of lanthanum obtained at temperatures equal respectively $727 \mathrm{~K}(\mathrm{a})$ and $628 \mathrm{~K}(\mathrm{~b})$.

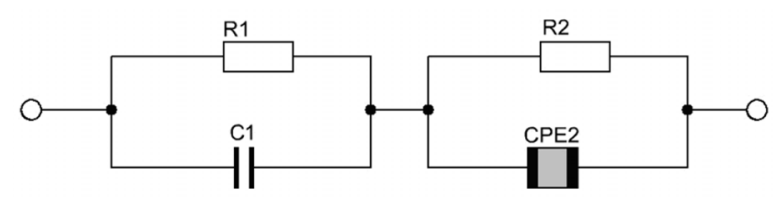

Fig. 6. Equivalent circuit used to represent the impedance response of BLT ceramics.

determined as:

$$
Z *_{C P E}=\left[A(j \omega)^{n}\right]^{-1}
$$

where $A$ is a constant that is independent of frequency, and $n$ is an exponential index which is the measure of distortion of $Z^{\prime \prime}\left(Z^{\prime}\right)$ characteristic. For an ideal "Debye" like behaviour, it stands that $n=1$, and CPE represents an ideal capacitor with the value $C=A$. The value of $n$ below 1 indicates that the frequency dependent capacitor. For $n=0$, CPE behaves like pure resistance with the value $R=1 / A$. The CPE element is usually used to explain phenomena on the grain boundary areas [11]. The proposed modification of equivalent circuit led to significant improvement in quality of the fits. The fitting procedures were done with ZView program. A careful deconvolution analysis of impedance spectra of investigated ceramics has been done. The typical results of such analysis estimated for BT, BLT2 and BLT4 sample at temperature equal $825 \mathrm{~K}$ are shown as example in Figure 7.

The comparison between raw data and fitting one points out the fairly good accordance and confirm the appropriate choice of equivalent circuit.

The follow comprehensive analysis of measuring data obtained for all discussed samples allows to determinate the resistivity of grain and grain boundary. Generally, the grain boundary resistivity $\left(R_{G B}\right)$ was found to be much higher than the grain one $\left(R_{G}\right)$. The small amount of La (up to 0.1 mol.\%) caused the decreasing of $R_{G}$ and $R_{G B}$ resistances. The further increase of La changes the tendency - the value of both resistances start to slowly increase for the content of La equal 0.2 and $0.3 \mathrm{~mol} . \%$. The rapid acceleration of the resistance growth is observed for 0.4 and $0.5 \mathrm{~mol} \%$ of La dopant. The adequate diagram
Table 1. Activation energy values calculated from impedance data for grain $\left(E_{G}\right)$ and grain boundary $\left(E_{\mathrm{GB}}\right)$ resistivity.

\begin{tabular}{ccc}
\hline Ceramics & $E_{G}(\mathrm{eV})$ & $E_{\mathrm{GB}}(\mathrm{eV})$ \\
\hline BT & 1.29 & 1.22 \\
BLT1 & 1.12 & 1.17 \\
BLT2 & 1.13 & 1.04 \\
BLT3 & 1.11 & 1.15 \\
BLT4 & 1.03 & 1.17 \\
BLT5 & 0.8 & 1.23 \\
\hline
\end{tabular}

of natural logarithm of obtained grain and grain boundary resistivity versus reciprocal absolute temperature was made (Fig. 8). The linear character of $\ln R_{G}(1 / T)$ and $\ln R_{G B}(1 / T)$ dependences shows the activation character of processes occurring in the grain and grain boundary. The slope of dependences significantly changes with the La content over the entire discussed temperature range, what is connected with the changes of activation energy obtained from the Arrhenius plots (Tab. 1).

For undoped $\mathrm{BaTiO}_{3}$ ceramics the activation energy of grain $\left(E_{G}\right)$ is closer to the grain boundary one $\left(E_{G B}\right)$. These results are consistent with the constriction zone model [22]. According to the model the electric contact of two phases is almost continuously. Additives of lanthanum ions in amount not exceeding 3 mol.\% caused decreasing of both activation energies, but the differences between them remain at the same small level. The more significant modification of $\mathrm{BaTiO}_{3}$ ceramics by La ions is connected with the sharp decline of $E_{G}$ and fast increase of $E_{G B}$. The difference in the value of grain and grain boundary might indicates a reduction in ionic mobility in the grain boundary [23]. In order to confirm the thesis described above the temperature dependence of blocking factor has been estimated for all discussed materials (Fig. 9). The blocking factor $\left(\alpha_{G B}\right)$ gives the fraction of electric carriers being blocked at the impermeable internal surface with respect to the total number of electric carriers in the sample. The blocking factor is defined from impedance spectroscopy parameter by the equation [24]

$$
\alpha_{G B}=\frac{R_{G B}}{R_{G B}+R_{G}} .
$$



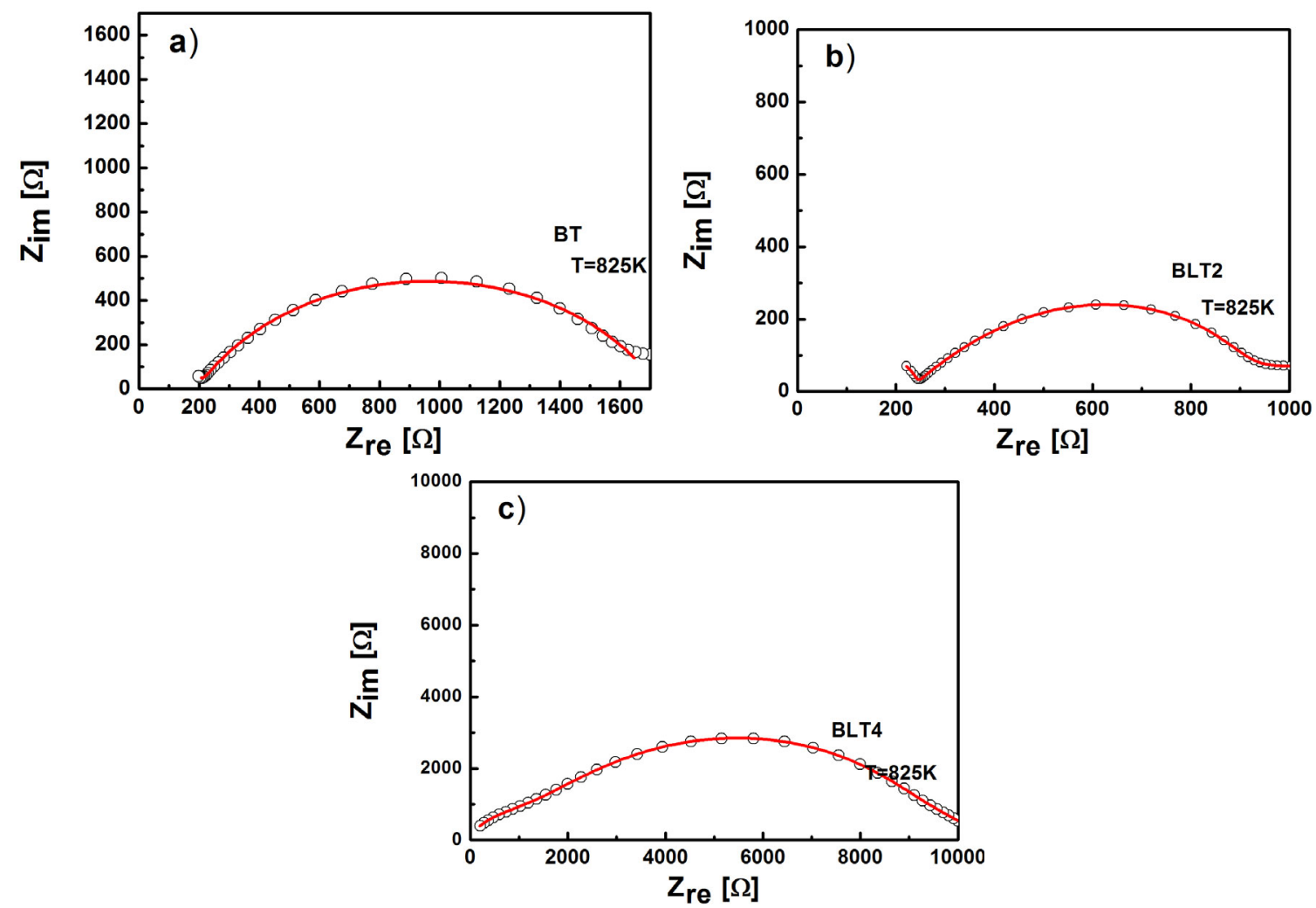

Fig. 7. Experimental AC impedance spectrum in complex plane (open circles) and modeled impedance spectrum using calculated values of circuit elements (solid line) for undoped $\mathrm{BaTiO}_{3}$ (a) and lanthanum modified BLT2 (b) and BLT4 (c).
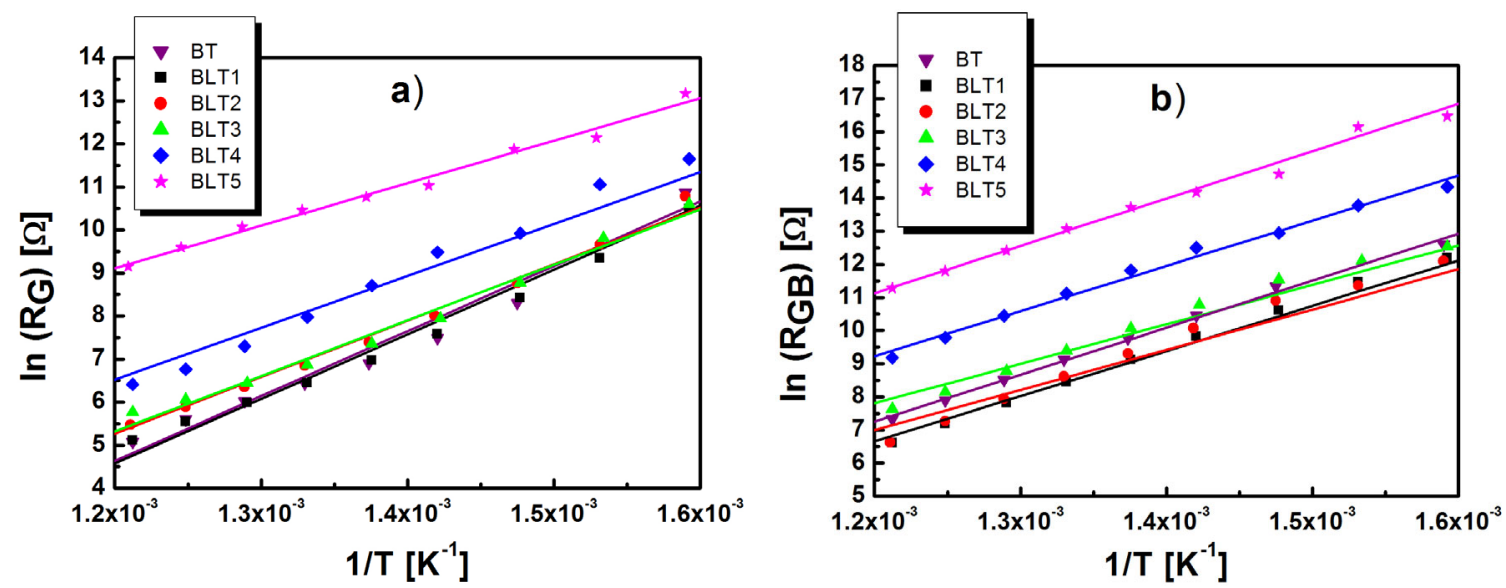

Fig. 8. Arrhenius plots for calculation of conduction activation energies of grain (a) and grain boundary (b).

It is shown that the blocking factor for small amount of lanthanum (up to $2 \%$ ) decreases and for higher concentration of admixture it increases again. The sample with the $5 \%$ of lanthanum content is characterized by the $\alpha_{\mathrm{GB}}$ higher than the undoped one.

\section{Conclusion}

The sol-gel method was successfully employed for the synthesis of the $\left(\mathrm{Ba}_{1-x} \mathrm{La}_{x}\right) \mathrm{Ti}_{1-x / 4} \mathrm{O}_{3}$ (BLT $\left.x\right)$ ceramic material and the obtained ceramics samples were high quality.
The results of impedance measurements pointed out the undeniable influence of lanthanum admixture on the electric properties of discussed ceramics. Generally the grain boundary resistivity $\left(R_{G B}\right)$ was found to be much higher than the grain one $\left(R_{G}\right)$. Only the small amount of La (up to $0.1 \mathrm{~mol} . \%$ ) caused the decreasing of both resistances. The further increase of La changes the tendency - the value of both resistances start to slowly increase for the content of La equal 0.2 and $0.3 \mathrm{~mol} \%$. The rapid acceleration of the resistance growth is observed for 0.4 and $0.5 \mathrm{~mol} \%$ of La. Basing on the temperature function of grain and grain boundary resistivity the activation 


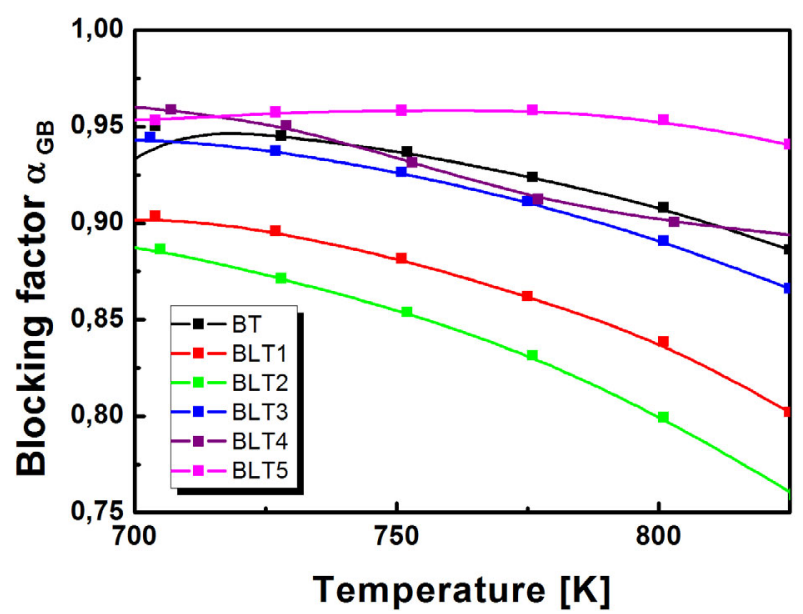

Fig. 9. Variation of the blocking factor with temperature for the $\mathrm{BaTiO}_{3}$ ceramics doped by lanthanum.

energy was obtained for all investigated samples. The values of both energies are comparable. That fact allows to assume, that for $\mathrm{BaTiO}_{3}$ ceramics modified by the lanthanum up to $0.3 \mathrm{~mol} \%$ the current flows in the same degree by grain boundaries and grain interiors. The situation is changes with higher amount of lanthanum admixture. The significant differences in activation energy are observed, namely the activation energy of grain sharply decline whereas the activation energy of grain boundary rapidly increase. The difference in the value of grain and grain boundary resistance might indicates a reduction of ionic mobility in the grain boundary.

The present research has been supported by National Research and Development Centre (NCBR) and National Science Centre (NCN) in years 2015-2018, as a research Project No. TANGO1/269499/NCBR/2015.

\section{References}

1. M.M. Vijatovic Petrovic, J.D. Bobic, R. Grigalaitis, B.D. Stojanovic, J. Banys, Acta. Phys. Pol. A 124, 155 (2013)

2. B. Wodecka-Dus, M. Plonska, D. Czekaj, Arch. Metall Mater. 58, 1305 (2013)
3. W. Cai, Ch. Fu, Z. Lin, X. Deng, W. Jiang, Adv. Mat. Res. 412, 275 (2012)

4. D. Kim, J. Kim, T. Noh, J. Ryu, Y. Kim, H. Lee, Curr. Appl. Phys. 12, 952 (2012)

5. N.H. Chan, M.P. Harmer, D.M. Smyth, J. Am. Ceram. Soc. 69, 507 (1986)

6. K. Osinska, G. Smalarz, B. Wodecka-Dus, D. Czekaj, Mater. Sci. Forum 730-732, 141 (2013)

7. B. Boukamp, Solid State Ionics 169, 65 (2004)

8. B.A. Boukamp, J. Electrochem. Soc. 142, 1885 (1995)

9. S. Rachna, S.M. Gupta, S. Bhattacharyya, Pramana 71, $599(2008)$

10. A. Kumar, N.M. Mumari, R.S. Katiyar, J. Alloys Compd. 469, 433 (2009)

11. Lily, K. Kumari, K. Prasad, R.N.P. Choudhary, J. Alloys Compd. 453, 325 (2008)

12. N. Thirumal Reddy, K. Madhavi, N.V. Prasad, G.S. Kumar, G. Prasad, IJRET 4, 397 (2015)

13. J.S. Kim, B.Ch. Choi, J.W. Chung, J.H. Jeong, J. Korean Phys. Soc. 52, 410 (2008)

14. A. Pelaiz-Barranco, I. Gonzalez-Carmenate, F. CalderonPinar, E. Torres-Garcia, Solid State Commun. 132, 431 (2004)

15. B. Harihara Venkataraman, K.B.R. Varma, J. Phys. Chem. Solids 64, 2105 (2003)

16. L. Zhigao, J.P. Bonnet, J. Ravez, J.M. Reau, P. Hagenmuller, J. Phys. Chem. Solids 53, 1 (1992)

17. J.S. Kim, J.N. Kim, Jpn J. Appl. Phys. 39, 3502 (2000)

18. D. Mancic, V. Paunovic, M. Vijatovic, B. Stojanovic, Lj. Zivkovic, Sci. Sintering 40, 283 (2008)

19. F.D. Morrison, A.M. Coats, D.C. Sinclair, A.R. West, J. Electroceram. 6, 219 (2001)

20. S. Markovic, M. Miljkovic, C. Jovalekic, S. Mentusd, D. Uskokovic, Mater. Manuf. Process. 24, 1114 (2009)

21. B. Jaffe, J. Am. Ceram. Soc. 41, 494 (1958)

22. J.E. Bauerle, J. Phys. Chem. Solids 30, 2657 (1969)

23. D.Y. Wang, A.S. Nowick, J. Solid State Chem. 35, 325 (1980)

24. C.R. Foschini, D.P.F. Souza, P.I. Paulin, J.A. Varela, J. Eur. Ceram. Soc. 21, 1143 (2001)

Open Access This is an open access article distributed under the terms of the Creative Commons Attribution License (http://creativecommons.org/licenses/by/4.0), which permits unrestricted use, distribution, and reproduction in any medium, provided the original work is properly cited. 